Marcos Ribeiro Botelho ${ }^{\mathrm{a}, \mathrm{b}}$

(iD) https://orcid.org/0000-0001-9142-9985

Mario Parreiras de Faria ${ }^{a}$

(iD) https://orcid.org/0000-0002-3496-8664

Carolina Tobias Retes Mayr ${ }^{\mathrm{a}}$

iD https://orcid.org/0000-0001-8404-7583

Leandro Magno Gomes de Oliveira ${ }^{\mathrm{a}}$

(iD) https://orcid.org/0000-0002-2290-6167

aMinistério do Trabalho e

Previdência, Secretaria de Trabalho,

Superintendência Regional do

Trabalho e Emprego em Minas Gerais.

Belo Horizonte, MG, Brasil.

bPontifícia Universidade Católica de Minas Gerais, Instituto de Educação Continuada. Belo Horizonte, MG, Brasil.

Contato:

Mario Parreiras de Faria

E-mail:

mariop@economia.gov.br

Os autores declaram que o trabalho não foi subvencionado e que não há conflitos de interesses.

Os autores informam que o trabalho não foi baseado em dissertação ou tese e que não foi apresentado em evento científico.

\section{Rompimento das barragens de Fundão e da Mina do Córrego do Feijão em Minas Gerais, Brasil: decisões organizacionais não tomadas e lições não aprendidas}

\author{
Barragem de Fundão and Mina do Córrego do Feijão \\ dams rupture in Minas Gerais, Brazil: untended \\ organizational decisions and unlearned lessons
}

\section{Resumo}

Introdução: rompimentos de barragens de rejeitos de mineração provocaram, em 2015, o maior desastre socioambiental e, em 2019, o maior acidente de trabalho do Brasil, ocasionando, respectivamente, a morte de 19 e 270 trabalhadores e moradores das áreas atingidas. Objetivo: identificar e discutir fatores gerenciais, de operação e de manutenção que podem contribuir para acidentes de rompimento de barragens, assim como sugerir medidas de aprimoramento de sistemas de gestão de empresas mineradoras, de políticas públicas e de normas técnicas que tratem da segurança de barragens. Métodos: ensaio com base em pesquisa documental. Foram utilizados relatórios oficiais sobre os acidentes, publicações técnicas e científicas e legislação pertinente ao tema. Resultados: fatores gerenciais, de operação, de manutenção, de engenharia e do ambiente de trabalho contribuíram para os rompimentos das barragens de Fundão e da mina do Córrego do Feijão. Discutem-se decisões gerenciais que levaram aos dois eventos e são apontadas medidas que poderiam ter evitado os acidentes. Conclusão: evidenciou-se a relevância da autonomia de técnicos e gerências na tomada de decisões, além da necessidade de alterar as normas técnicas utilizadas por empresas e os critérios de licenciamento e controle estatal de atividades que implicam grande risco ambiental e social.

Palavras-chave: acidente de trabalho; rompimento de barragem; gestão de riscos; saúde do trabalhador.

Keywords: occupational accidents; dam collapse; risk management; occupational health.

\begin{abstract}
Introduction: the rupture of mine-tailing dams in Brazil accounted for the largest socio-environmental disaster in 2015, and for the major work-related accident in 2019, causing, respectively, the death of 19 and 270 workers and residents of the affected areas. Objective: this study aimed to identify and discuss management, operational, and maintenance factors that may lead to dam failure, as well as suggest measures to improve management systems of mining companies, public policies, and technical regulations related to dam safety. Methods: essay based on documentary research making use of the accidents official reports, technical and scientific publications, and relevant legislation. Result: factors related to management, operation, maintenance, engineering, and work environment contributed to the dams rupture of Barragem do Fundão and Mina do Córrego do Feijão. We discussed management decisions that led to both events, as well as measures that could have prevented them. Conclusion: the findings highlight the relevance of the technicians' and managers' autonomy in decision-making, besides indicating the need for changing technical standards maintained by companies, and state control, and licensing criteria for activities involving great environmental and social risk.
\end{abstract}

Recebido: 01/08/2019

Revisado: 08/06/2020

Aprovado: 30/06/2020 


\section{Introdução}

Os rompimentos de barragens de rejeitos de minério ocorridos no Brasil acarretaram oportunidades de aprendizagem organizacional para as empresas envolvidas e de reflexão sobre o papel dos órgãos reguladores nesse processo. A investigação aprofundada dessas catástrofes motiva melhorias na legislação, na regulação, nas práticas e nos métodos de prevenção e segurança ${ }^{1,2}$.

No Brasil, existem atualmente 84 barragens de mineração construídas ou alteadas pelo método "a montante" ou por método declarado como "desconhecido" na Política Nacional de Segurança de Barragens (PNSB), sendo que a maioria delas está localizada em Minas Gerais ${ }^{3}$. Barragens do tipo "a montante" são as que apresentam maior risco de rompimento, pois os diques de alteamento são construídos com rejeito de mineração e se apoiam no rejeito já lançado no reservatório.

Em março de 2020, das 431 barragens existentes em estabelecimentos de mineração no Brasil, 47 estavam interditadas, sendo 17 delas alteadas a montante ${ }^{4}$.

O rompimento da Barragem de Rejeitos de Fundão (BRF) ocorreu em 5 de novembro de 2015, no município de Mariana, Minas Gerais. A BRF, propriedade da Mineradora Samarco S.A., uma joint-venture entre a brasileira Vale S.A. e a anglo-australiana BHP Billiton, possuía diques alteados a montante e comportava, à época, cerca de 55 milhões de metros cúbicos de rejeitos decorrentes do processo de beneficiamento do minério de ferro por via úmida. A massa de rejeitos percorreu aproximadamente 650 quilômetros por todo o vale do Rio Doce, chegando à sua foz, no litoral do estado do Espírito Santo, e impactando toda a fauna e a flora em seu percurso, atingindo cerca de 1.587 hectares de vegetação nas suas margens. Populações de 39 municípios de Minas Gerais e do Espírito Santo ainda sofrem prejuízos socioeconômicos advindos da maior tragédia socioambiental do Brasil. Em termos de perdas humanas, morreram 14 trabalhadores da BRF e 5 moradores do distrito de Bento Rodrigues, há 8 quilômetros a jusante da BRF5.

Algum aprendizado poderia ter sido colocado em prática com o rompimento da BRF para que outro evento desta magnitude não se repetisse. Mas, no dia 25 de janeiro de 2019, a Barragem I (BI), de rejeitos, também alteada a montante, localizada na Mina do Córrego do Feijão, no município de Brumadinho, Minas Gerais, de propriedade da Vale S.A., rompeu-se da mesma forma que a BRF. Apesar da menor quantidade de rejeitos armazenados, cerca de 11,7 milhões de metros cúbicos, grande parte chegou ao Rio Paraopeba e impactou o fornecimento de água a várias cidades da região, como Brumadinho, Pará de Minas e a capital do estado, Belo Horizonte. Várias propriedades rurais nas margens do Córrego do Feijão e do Rio Paraopeba também foram atingidas. As alterações na turbidez e nos níveis de metais na água são persistentes e têm sido motivo de preocupação e de vigilância constantes das autoridades, assim como a saúde dos militares do Corpo de Bombeiros que atuaram e ainda atuam no resgate dos corpos até a data de elaboração deste artigo. Esse evento se destaca como o maior acidente de trabalho do Brasil, pois 258 trabalhadores perderam a vida, sendo 12 da Vale, 118 terceirizados, 3 estagiários e mais 10 que trabalhavam fora da mina. Outras 64 trabalhadores foram lesionadas e afastadas do trabalho. Além disso, vários cidadãos que viviam a jusante da BI e turistas hospedados em uma pousada na mesma região foram soterrados pelos rejeitos ${ }^{6}$.

Nesse contexto, os objetivos deste ensaio são identificar e discutir fatores gerenciais, de operação e de manutenção que podem contribuir para acidentes de rompimento de barragens, assim como sugerir medidas de aprimoramento de sistemas de gestão de empresas mineradoras, políticas públicas e normas técnicas que tratem da segurança de barragens.

\section{Métodos}

Trata-se de ensaio baseado em pesquisa documental. Como marco referencial, utilizou-se a teoria do acidente organizacional trazida pelos autores Llory $^{7}$ e Llory e Montmayel ${ }^{8}$. Para esses autores, analisar e compreender eventos complexos, como os abordados aqui, implica em explicá-los para além dos fatores técnicos proximais. As causas indiretas, subjacentes e latentes ou não imediatamente visíveis devem ser encaradas como produto da organização da segurança.

Nesse sentido, buscou-se analisar documentos disponíveis com dados sobre os projetos iniciais das barragens, os resultados das auditorias contratadas previamente pelas empresas, as anomalias detectadas, as medidas de controle e as decisões gerenciais tomadas ao longo de seu funcionamento. Com esse propósito, foram utilizados os relatórios de análise dos acidentes de trabalho objetos deste ensaio, elaborados pela Superintendência Regional do Trabalho e Emprego em Minas Gerais ${ }^{5,6}$.

Além desses documentos, consultou-se o relatório produzido por técnicos contratados pela Samarco e a peça acusatória do Ministério Público Federal no âmbito da Justiça Federal no caso da $\mathrm{BRF}^{9}$ e, também, recorreu-se à legislação nacional que estabelece as regras básicas sobre a segurança de barragens ${ }^{10,11}$.

As informações coletadas sobre as barragens abrangeram desde os projetos iniciais até os 
elementos disponíveis na época dos rompimentos. No caso da BRF foram recolhidos dados a partir do projeto de 2007 até novembro de 2015 e, no caso da $\mathrm{BI}$, a documentação compreendeu desde o projeto inicial datado de 1975 até o seu rompimento em janeiro de 2019.

Além disso, buscaram-se informações referentes ao rompimento da BRF e da BI publicadas em livros e artigos técnicos e científicos. A busca de artigos em periódicos científicos foi feita nas bases MEDLINE, Scopus e SciELO, utilizando os seguintes descritores associados ao operador booleano AND: acidente de trabalho, barragem de rejeitos, gestão de riscos.

\section{Resultados}

A partir da análise do levantamento de dados realizado, foram identificados cinco blocos de fatores que podem ter contribuído para os acidentes nas duas barragens: gerenciais, de operação, de manutenção, de engenharia e do ambiente de trabalho.

Os resultados sobre o rompimento da BRF e da BI serão apresentados separadamente.

\section{Rompimento da BRF}

\section{Fatores gerenciais}

A precificação do minério de ferro, como qualquer outra commodity, se dá no mercado internacional e as decisões gerenciais e de investimentos são realizadas ou postergadas em função desse mercado. Por outro lado, o avanço tecnológico associado à alta demanda desse minério tem permitido explorar jazidas com baixos teores, levando à geração de maiores volumes de rejeitos ${ }^{12,13}$.

A Samarco, aproveitando o boom da produção mineral brasileira, que cresceu 550\% entre 2001 e 2011, ampliou sua produção, construindo novas usinas de beneficiamento, a última em $2014^{14}$. Em 2008, com a intensa produção de minério, a barragem de rejeitos até então utilizada pela empresa chegou a seu limite de armazenamento, sendo necessária a construção da BRF, que passou a funcionar em dezembro daquele ano ${ }^{5}$. A BRF foi alteada pelo método a montante, que é o mais barato, porém o mais inseguro, uma vez que os diques de alteamento são construídos com e sobre o próprio rejeito ${ }^{15-17}$.

Logo no $5^{\circ}$ mês de armazenamento, a BRF apresentou surgências e, mesmo com problemas estruturais e de drenagem ao longo da sua operação, o lançamento de rejeitos e seu alteamento não foram paralisados. Nem mesmo quando apareceram grandes trincas no barramento, algumas com 200 metros de comprimento em agosto de 2014, interrompeu-se o lançamento de rejeitos para que uma solução definitiva de engenharia fosse implantada ${ }^{17}$.

O projeto da BRF previu dois diques: o Dique 1 armazenaria os rejeitos arenosos e o Dique 2 os rejeitos finos e a água. Por decisão da empresa, em meados de 2011, foi aberto um canal entre os dois diques. Com o surgimento de problemas estruturais subsequentes envolvendo as galerias de drenagem principal e secundária, tornou-se necessário o redirecionamento da água e dos rejeitos finos do reservatório do Dique 2 para o Dique 1. Estes rejeitos finos foram depositados junto à ombreira esquerda, sobre a qual, futuramente, seriam depositados rejeitos arenosos e construídos diques de alteamento ${ }^{16}$. Em agosto de 2012, o canal foi fechado e, em seguida, construíram-se novos alteamentos sobre os rejeitos finos.

Com os problemas ocorridos na drenagem inicial da BRF, que obrigaram a empresa a recuar o eixo do barramento, foi necessária a construção de vários drenos adicionais, como na região do recuo do eixo e nas ombreiras esquerda e direita, ainda em construção na ocasião do rompimento ${ }^{5}$.

Após a ocorrência das grandes trincas na região do recuo do eixo, em agosto de 2014, o Independent Tailings Review Board (ITRB), contratado pela Samarco para avaliar suas barragens de rejeitos, apontou, em um relatório de novembro de 2014, que deveriam ser executados, no menor prazo possível, as obras de retorno ao eixo original do projeto para restabelecer as condições de estabilidade. Contudo, um ano após a recomendação, as obras ainda não haviam sido concluídas 5 .

Destaca-se que a produção da Samarco aumentou $40 \%$ nos quinze meses que antecederam o rompimento da BRF, com o consequente aumento na disposição de rejeitos na barragem, que já se mostrava fragilizada desde o início de sua operação, o que poderia ser mais um fator contribuinte para sua ruptura ${ }^{13}$.

\section{Fatores de operação}

A BRF deveria dispor, conforme seu manual de operação de 2012, de uma praia mínima de 200 metros de largura ${ }^{5}$, cuja função é afastar o material fino e a água sobrenadante do talude ${ }^{\mathrm{C}}$ de montante

c Talude é qualquer superfície inclinada em relação à horizontal que delimita uma massa de solo, rocha ou outro material qualquer (minério, escória, lixo etc.). Os taludes podem ser naturais (encostas) ou construídos em forma de cortes e aterros. 
do barramento. Morgenstern et al. ${ }^{18}$ relataram que, em várias ocasiões, entre 2011 e 2012, a largura da praia não atendia ao critério mínimo de 200 metros de largura, às vezes chegando a 60 metros da crista. Em fevereiro de 2014, a largura da praia junto à ombreira direita chegou a ser de apenas 80 metros $^{18}$. Em 6 de outubro de 2015, a praia, junto à ombreira esquerda, estava com 100,54 metros. Em 14 de outubro, apresentou largura de 186,95 metros e, em 21 de outubro, alcançou 192,99 metros $^{5}$.

Ressalta-se que, quanto mais perto da barragem estiver a água do lago, maior será o nível da linha freática dentro do reservatório, o que pode saturar os diques.

\section{Fatores de manutenção}

A BRF teve uma manutenção precária durante sua operação, que foi caracterizada por: erosões de taludes, vegetação arbustiva em vários locais da barragem, ausência de canaletas, canaletas trincadas, com pouca declividade ou assoreadas, tubulações rompidas, falhas ou ausência de grama nos taludes, cupinzeiros e formigueiros, conforme apontaram relatórios de auditoria externa contratados pela Samarco, denotando um atraso ou mesmo a falta de correção das anomalias. Esses aspectos dificultavam a drenagem interna e o escoamento da água de chuva, permitindo seu acúmulo e penetração nos diques de alteamento ${ }^{5}$. A correção das anormalidades deveria ser realizada no menor tempo possível, uma vez que sua persistência comprometia a estabilidade e segurança da barragem. Entretanto, não foi possível identificar os motivos do atraso na adoção das medidas corretivas das anomalias verificadas ao longo da operação da barragem.

\section{Fatores de engenharia}

No Brasil, as empresas mineradoras são obrigadas a contratar auditorias externas para a produção de relatórios de inspeção de segurança regular das barragens. À época do rompimento da BRF, esses relatórios deveriam ser produzidos anualmente ${ }^{9}$ e, após maio de 2017, a cada seis meses ${ }^{10}$. Caso a barragem apresente condições de estabilidade satisfatórias, emite-se a Declaração de Condição de Estabilidade (DCE).

O fator de segurança de estabilidade (FS) foi definido pela ABNT/NBR n ${ }^{\circ} 13.208 / 2006$, revisada em 2017. Para a situação drenada o FS mínimo é de 1,50. Porém essa norma não estabelece o FS mínimo para a situação não drenada (quando a poropressão presente nos solos não consegue ser dissipada) e recomenda que os consultores usem boas técnicas de engenharia aplicáveis para calcular o FS para essa situação. Até 2019 era comum adotar um FS de 1,30 para a situação não drenada.
Em setembro de 2015, a Samarco obteve a DCE para a BRF baseada em um relatório de inspeção de segurança regular que apontou FS de 1,68 para a condição drenada, mas não apresentou o cálculo do FS para a situação não drenada ${ }^{5}$.

Entretanto, após o surgimento das grandes trincas verificadas no barramento em agosto de 2014, o ITRB recomendou que deveria se considerar nos cálculos de estabilidade o ângulo de atrito de $28^{\circ}$ para os rejeitos arenosos e não o de $35^{\circ}$, como vinha sendo adotado até então pela empresa de auditoria. Quanto maior o ângulo de atrito de um material, maior o FS. Porém, o ITRB não informou qual seria a redução no FS se fosse utilizado o ângulo de atrito de $28^{\circ}$ recomendado por ele. Contudo, a empresa continuou utilizando o valor de $35^{\circ}$, mantendo elevado o FS calculado e mascarando a verdadeira situação de estabilidade da $\mathrm{BRF}^{5}$.

\section{Fatores do ambiente de trabalho}

Quando do rompimento da BRF, não havia sirenes para alertar trabalhadores e moradores das comunidades a jusante da barragem em caso de emergência. No momento em que a barragem começou a se liquefazer, trabalhadores que estavam na barragem tentaram manter contato com outros via rádio de comunicação. A maioria conseguiu se safar da massa de rejeitos, deslocando-se para locais elevados às margens da barragem, a pé, de carro, de caminhão e até de motocicleta. Os trabalhadores das empresas terceirizadas não foram capacitados para emergências envolvendo rompimento de barragem ${ }^{5}$.

\section{Rompimento da BI}

Fatores gerenciais

A BI, que também foi alteada pelo método a montante, teve seu dique inicial construído em 1976, pela empresa Ferteco Mineração S.A., adquirida pela Vale em 2001.

Em 2011, a Vale decidiu descaracterizar (desmanchar) a BI, projetando retirar todo o seu rejeito, beneficiá-lo e transformá-lo em produto vendável. Porém a barragem estava com nível freático - lençóis de água no interior dos rejeitos - muito elevado e seria necessário rebaixá-lo para realizar sua descaracterização. Somente em 2016, a BI deixou de receber rejeitos, quando a empresa passou a beneficiar o minério da mina por meio de processo a seco ${ }^{6}$.

Em julho de 2017, apontou-se como solução para o rebaixamento do nível freático, a construção de poços de rebaixamento. Em janeiro de 2018, em documento que tratava de alternativas para incremento da segurança da BI quanto à liquefação, foram sugeridas outras opções à empresa: rebaixamento do 
nível piezométrico com poços verticais, construir novos taludes ou bermas para garantir a estabilidade da barragem e facilitar a drenagem ${ }^{6}$.

Contudo, a Vale decidiu pela execução de drenos horizontais profundos (DHPs), iniciando a perfuração em abril de 2018. Em 11 de junho de 2018, durante a perfuração de um DHP na base da barragem, a água injetada no furo surgiu em posição mais elevada, dentro de uma canaleta, constituindo uma fratura hidráulica do maciço, motivo pelo qual a empresa abandonou a perfuração dos DHPs. Sete meses depois, até 25 de janeiro de 2019, quando do rompimento da BI, ainda não haviam sido adotadas outras medidas efetivas para rebaixamento do lençol freático ${ }^{6}$.

Em março de 2018, foi instalado na BI um radar interferométrico cuja função era monitorar deslocamentos dos taludes ${ }^{6}$. Desde a sua instalação, registraram-se deslocamentos dos taludes, sendo que, em 18 de janeiro de 2019 (sete dias antes do rompimento), o operador do radar informou à gerência de geotecnia da empresa a ocorrência de uma movimentação maior (cerca de $15.000 \mathrm{~m}^{2}$ ) em uma área da barragem. Tal informação não foi valorizada pela gerência, uma vez que não se encontrou registro de providências para retirar todas as pessoas que poderiam ser afetadas pelo rompimento da barragem.

A empresa sabia que a BI era a mais perigosa de suas barragens, pois tinha maior probabilidade de rompimento por liquefação ${ }^{6}$. Esse fenômeno ocorre quando os rejeitos arenosos armazenados ficam saturados, perdem a resistência ao cisalhamento ${ }^{\mathrm{d}}$ e, quando submetidos a um gatilho, comportam-se como uma massa fluída, levando ao rompimento da estrutura.

Constatou-se que muitos problemas apresentados na estrutura se repetiram ano após ano e muitas anomalias detectadas só foram sanadas após o decurso de um longo prazo, caracterizando certo descaso com a conservação do barramento. Somente quando houve interesse econômico no material armazenado na barragem, a empresa decidiu melhorar sua drenagem ${ }^{6}$.

Como limitação para uma análise mais profunda dos fatores gerenciais, salienta-se que, com a judicialização dos eventos descritos, empregados da Vale foram afastados, dificultando a busca das possíveis explicações sobre a origem das decisões gerenciais e organizacionais tomadas ao longo da história da barragem. Destaca-se que o gerente operacional da mina faleceu no acidente e outros gerentes, diretores e responsáveis técnicos tiveram prisão temporária decretada, constituindo obstáculos à análise.

\section{Fatores de operação}

O primeiro manual de operação da barragem BI foi elaborado somente em 2007, determinando uma largura mínima de praia de 150 metros. Vários documentos apontavam que, em 2002, 2006, 2012 e 2015, a largura da praia era inexistente ou inferior ao especificado no manual de operação ${ }^{6}$.

Vários relatórios de empresas de auditoria contratadas pela Vale apontaram a falta de registros sobre a existência de drenagem de fundo no dique inicial da $\mathrm{BI}^{6}$.

As Fichas de Inspeção Regular (FIRs), preenchidas quinzenalmente pela Vale, evidenciaram a falta de cuidado na operação da BI. Por exemplo, em 2015, 79\% das inspeções informaram o lançamento de rejeitos sem critério, ocasionando a formação de camadas impermeáveis junto ao barramento que, por sua vez, resultaram na formação de lençóis freáticos suspensos ${ }^{6}$. Em 2018, foram relatadas surgências em 16 inspeções regulares realizadas, correspondendo a $67 \%$ das inspeções.

\section{Fatores de manutenção}

Os relatórios elaborados por empresas de consultoria anualmente apontavam inúmeros problemas na BI, agravados pela permanência contínua de gado pastando sobre a barragem, destruindo a grama sobre os taludes e quebrando tubos e canaletas de drenagem ${ }^{6}$.

Das FIRs emitidas de janeiro de 2015 a janeiro de 2019, 90\% mostram problemas com a drenagem superficial, 53\% indicam presença de vegetação alta ou arbustiva em alguma região da barragem e $45 \%$ relatam a existência de recalques, deformações, trincas e/ou pontos de erosão nos taludes do barramento, caracterizando uma manutenção precária da estrutura ${ }^{6}$.

\section{Fatores de engenharia}

As consultorias contratadas pela empresa adotavam o FS de 1,30 para a situação não drenada do barramento. Em 2016, um relatório de auditoria já apontava que a barragem apresentava FS próximo de 1. Quando o relatório de inspeção de segurança regular de setembro de 2018 apontou FS de 1,09, a consultoria contratada fez uso de uma teoria até então

d Cisalhamento é o deslocamento da massa dos taludes em planos diferentes, mantendo o volume constante 
não utilizada no Brasil, indicando que o FS mínimo seria de 1,05 e, assim, atestou a estabilidade da barragem mesmo com um FS tão baixo para a situação não drenada ${ }^{6}$.

\section{Fatores do ambiente de trabalho}

As sirenes instaladas a jusante da BI não foram acionadas no momento da ruptura, impossibilitando alertar moradores e trabalhadores, inclusive os que almoçavam no refeitório, localizado a cerca de 1 quilômetro a jusante. Alguns trabalhadores que estavam fora do refeitório, ao verem a onda de rejeitos, conseguiram se deslocar para partes mais altas da mina.

A capacitação prática dos trabalhadores da Vale abordando uma situação de rompimento de barragem ocorreu apenas em 23 de outubro de 2018, e abrangeu apenas os que laboravam no momento da capacitação. Os trabalhadores do turno noturno não participaram desse simulado. Não se comprovou a capacitação de trabalhadores terceirizados do complexo da mina ${ }^{6}$.

\section{Discussão}

$\mathrm{O}$ acidente da BI constitui o $8^{\circ}$ rompimento de barragens de rejeitos em Minas Gerais desde $1985^{19}$.

A Samarco optou pelo método de alteamento a montante para a BRF em 2007, assumindo os riscos de um método construtivo inseguro. Apesar de haver um nível freático elevado junto à ombreira esquerda e várias surgências por toda a barragem, a empresa não paralisou em nenhum momento o seu alteamento, pois isso interromperia a produção da mina, afetando o faturamento e o cumprimento de compromissos contratuais da empresa, com impactos negativos na distribuição de lucros para os acionistas ${ }^{6}$.

A BI também foi alteada pelo método a montante e estava instalada há 25 anos quando a Vale adquiriu a mina em 2001. Somente no início de 2018, um estudo apontou quatro opções para o rebaixamento do nível freático da barragem para torná-la mais segura: poços verticais, lavra da barragem, retaludamento e berma de estabilização ${ }^{6}$. Contudo, até o dia do rompimento, o problema do nível freático elevado não havia sido solucionado, assim como não foi tomada qualquer medida para transferir as áreas administrativas e o refeitório para fora da área de inundação ${ }^{6}$.

Quanto à operação das barragens, não foi dada a devida atenção à largura das praias, que em várias ocasiões ficaram em desacordo com o manual de operação das barragens, contribuindo para que a linha freática permanecesse junto aos diques de alteamento ${ }^{6}$.
A manutenção mostrou-se crítica nas duas barragens, com canaletas de drenagem assoreadas ou quebradas, taludes com erosões ou sem grama, bermas com declividade errada e saídas de drenos quebradas. A presença de gado sobre os taludes e bermas da BI demonstra o descaso com a construção, pois, além de se alimentarem da grama nos taludes, os animais quebravam os tubos de drenagem interna e as canaletas de drenagem externa.

Os parâmetros geotécnicos utilizados no cálculo do FS das duas barragens eram inadequados, possibilitando a obtenção das DCEs pelas empresas. Isso permitiu à Samarco continuar o lançamento de rejeitos na BRF e, no caso da BI, proporcionou à Vale receber autorização para sua descaracterizão ${ }^{5,6}$.

No tocante às sirenes para alertar os trabalhadores e a população a jusante das barragens, verifica-se o despreparo das empresas para a situação de rompimento das estruturas. A Samarco não tinha qualquer sirene instalada nas proximidades da BRF e nos distritos a jusante. No caso da BI, as sirenes não foram acionadas por ocasião de seu rompimento. Apesar da existência de um sistema de videomonitoramento na $\mathrm{BI}$, não havia ninguém na hora do almoço que pudesse alertar o responsável pelo Plano de Ação de Emergência para Barragens de Mineração (PAEBM) para que ele ordenasse o acionamento das sirenes ${ }^{6}$.

Os rompimentos de barragens de rejeitos exigem uma reflexão aprofundada para extrair lições que permitam melhorar a prevenção de eventos desta natureza e propiciar elementos para promover uma mudança expressiva no modelo de desenvolvimento nacional, que favorece a exploração predatória e a exportação de bens primários, propiciando riscos e impactos negativos na segurança desses sistemas de produção. Os acidentes ampliados e de trabalho aqui abordados, e suas consequentes catástrofes socioambientais, revelam falhas nos processos de gestão da segurança ocupacional e ambiental das empresas, que foram incapazes de garantir a segurança das barragens, dos empreendimentos, de seus trabalhadores e das populações afetadas ${ }^{20}$. Outro aspecto a ser destacado é que o processo de financeirização de empresas que buscam lucro imediato tem como consequências o corte de custos operacionais e a redução de investimentos na segurança operacional, levando a gestão dessas corporações a desconsiderar alertas sobre um desastre iminente no sistema e adiar a adoção das medidas corretivas necessárias ${ }^{2}$.

Cabe assim indagar quais imperativos econômicos ou financeiros e de gestão de desempenho entraram em jogo para influenciar as decisões técnicas ou a manutenção de anomalias e na valorização de sinais identificados como causas básicas desses acidentes. Outro aspecto a ser considerado é a complexa 
rede de determinantes socioeconômicos, culturais, organizacionais e técnicos que podem influenciar a gênese dos acidentes ${ }^{21}$. Neste sentido, Armstrong, Petter e Petter ${ }^{22}$ apresentam a hipótese de que o sistema de bonificação anual das empresas encorajaria gestores a cortar custos e aumentar a produção e seus bônus anuais, o que poderia ser um fator chave no aumento de ocorrência de acidentes.

Além disso, a dependência econômica dos estados, municípios e das comunidades próximas das minerações, focada nos benefícios imediatos decorrentes da oferta de emprego e recolhimento de impostos, leva a uma aceitação relativamente passiva dos impactos socioambientais e dos riscos advindos destes empreendimentos ${ }^{23}$.

Se os aspectos mencionados não forem considerados, a simples mudança nos métodos construtivos de barragens de rejeitos pode não ser suficiente para evitar acidentes como os ocorridos, visto que os sistemas e dispositivos tecnológicos não são isentos de risco e apresentam limites, imperfeições e incertezas ${ }^{21,24}$.

Acidentes ampliados, como rompimentos de barragens de rejeitos, não possuem uma causa única, mas resultam de uma combinação de fatores acumulados ao longo do tempo. A origem dessas ocorrências pode ser explicada por decisões técnico-organizacionais, ou mesmo políticas, tomadas ao longo da história do sistema. No caso do rompimento da BRF e da BI, decisões gerenciais deixaram de ser tomadas em relação à segurança da operação e manutenção do sistema de disposição de rejeitos, propiciando um "período de incubação” antes da ruptura catastrófica. Turner, citado por Llory e Montmayeul $^{8}$, aponta que o período de incubação se caracteriza pelo aparecimento de sinais anunciadores de um possível acidente. Segundo os autores, tais sinais podem evoluir de fracos e repetitivos (incidentes menores, embora frequentes) a incidentes e sinais mais graves, até aos chamados quase acidentes, aqueles em que faltou pouco para que acontecesse uma catástrofe, indicadores de uma disfunção latente e profunda, que levam a um fracasso na organização da segurança da empresa.

Verifica-se ainda que os "sinais precursores" dos acidentes $^{7}$ não foram considerados seriamente pelas empresas. Entretanto, o mais difícil não é identificar esses sinais, mas sim atribuir-lhes um valor e reconhecer a gravidade e urgência das situações a que se referem. Porque, nos casos analisados, os sinais existentes não foram reconhecidos a tempo e tratados com a urgência necessária? Até que ponto fazia sentido para os gestores a adoção de tentativas de correção dos defeitos do sistema para manter sua integridade e seu funcionamento, mas que logo apresentavam outros defeitos?
Indagamos até quando os sinais precursores sequenciais desses acidentes foram encarados como "sinais mistos": sinais de um perigo potencial seguidos por sinais de que tudo ficou bem, convencendo os engenheiros de que o problema foi diagnosticado com sucesso, corrigido e, assim, o risco era aceitá$\mathrm{vel}^{25}$. A partir daí, esses sinais passariam a ser encarados como "sinais de rotina" que, mesmo sendo reconhecidos como potencialmente sérios, perdem sua gravidade quando eventos semelhantes ocorrem em sequência, os métodos de avaliação e resposta a eles se estabilizam e não levam a um acidente ${ }^{25}$. Daí se evolui para o que Vaughan ${ }^{25}$ denomina "normalização”, quando os gestores evidenciam que o projeto não está tendo o desempenho esperado, mas começam a aceitar essas evidências como não desviantes, pois o acidente não acontece. Ou, mesmo, apresentam uma crença cega nos parâmetros e medidas técnicas postos pela engenharia e seus paradigmas clássicos, que propicia um processo de naturalização de procedimentos questionáveis do ponto de vista da gestão de risco, acarretando um acúmulo de falhas e tornando as estruturas cada vez menos seguras ${ }^{26}$.

\section{Llory $^{7}$ lembra que}

[...] os operadores e a gerência de produção contri-
buem para que, num primeiro momento, as condi-
ções de segurança sejam garantidas da melhor ma-
neira possível, mas acabem cedendo, renunciando
a resistir, curvando-se em posições fatalistas muito
defensivas e prejudiciais para a segurança aqui e
agora, pois as possibilidades de aviso, de alerta de
um acidente em potencial iminente podem achar-se
muito alteradas, até aniquiladas. Essa situação pode
agravar-se ainda mais pela insegurança no emprego,
pela incerteza do amanhã... (p. 134-135)

No caso desses acidentes devemos lembrar as palavras de Reason, citado por Mendel $^{26}$ :

\begin{abstract}
Antes de considerarmos os operadores, os principais causadores do acidente, é preciso compreender que eles são herdeiros dos defeitos do sistema, criados por uma concepção ruim, uma instalação malfeita, uma manutenção deficiente e por decisões errôneas da direção [...] quanto mais afastados os indivíduos das atividades de primeira linha e, assim, dos riscos diretos, mais perigosos, em potencial para o sistema. (p. 12-13)
\end{abstract}

É possível destacar algumas lições que deveriam ter sido aprendidas no caso do rompimento da BRF e que contribuiriam para evitar desastres em barragens de rejeitos:

- A eficácia do sistema de drenagem deve ser aprimorada até que se obtenha o FS mínimo estabelecido em normas e regulamentos;

- Instrumentos de auscultação ou monitoramento (como piezômetros, indicadores de 
nível de água e inclinômetros) devem ser adequadamente mantidos e substituídos sempre que necessário;

- A Carta de Risco, documento que aponta os níveis de referência para os instrumentos de auscultação, deve ser revisada sempre que novos instrumentos forem instalados;

- Surgências em estruturas superficiais, nos taludes e no pé das barragens devem ser valorizadas, pois indicam a falência do sistema de drenagem interno;

- A largura da praia de rejeitos deve ser respeitada conforme determinado no manual de operação da barragem;

- Investigações geotécnicas devem ser aprofundadas para que os parâmetros que caracterizam os resíduos e os solos dos diques e das fundações sejam de fato conhecidos;

- O sistema de comunicação de emergência, para alertar trabalhadores e a comunidade a jusante das barragens, deve ser acionado de imediato após a constatação de falha;

- As empresas de auditoria devem ser prudentes na utilização dos parâmetros de resistência dos solos e dos rejeitos, tendo em vista a sua grande variabilidade; $\mathrm{e}$

- A alta direção das empresas deve ser rápida na tomada de decisões após as recomendações feitas pelas auditorias.

\section{Considerações finais}

Nos casos analisados, várias questões permanecem em aberto: qual era o nível real de autonomia dos técnicos em decisões que poderiam afetar a rentabilidade da empresa ou mesmo a continuidade das operações? Como essas avaliações técnicas são consideradas em sistemas de prestação de contas corporativas, que, em tese, deveriam confirmar as políticas de responsabilidade socioambiental declaradas da alta gerência das empresas?

Para nós, autores deste ensaio, a tomada das decisões na construção, operação, manutenção e controle de tecnologias e sistemas de produção que apresentam riscos de causar desastres, como no caso de barragens de rejeitos, somente pode avançar com a adoção de um sistema de comunicação claro e eficaz entre as diversas instâncias das organizações, explicitando responsabilidades e riscos socioambientais, associado ao monitoramento e controle de todas as partes interessadas, inclusive com a participação das comunidades potencialmente afetadas.

Por fim, a análise desses acidentes indica a necessidade de uma mudança profunda nas normas técnicas brasileiras relativas a barragens de rejeitos, que devem adotar fatores de segurança mais conservadores para as condições drenada e não drenada.

Do ponto de vista da fiscalização estatal, devem ser alterados os critérios de regulamentação, licenciamento e controle dessas estruturas, com empoderamento dos órgãos licenciadores e fiscalizadores estaduais e federais. Estes devem ser dotados de um corpo de profissionais em quantidade suficiente para a vigilância do grande número de barragens de rejeitos existente no país, com infraestrutura de apoio e competência técnica compatível com a complexidade dessas estruturas, associadas a mudanças legislativas que impliquem controle rigoroso do sistema de automonitoramento, eliminando a autodeclaração de estabilidade.

Cabe destacar que, após o rompimento da BI, o governo do estado de Minas Gerais promulgou a Lei ${ }^{0} 23.291 / 2019^{27}$, determinando regras mais rígidas para a mineração no estado, dentre as quais a proibição da instalação de barragens alteadas a montante. No nível federal, a Agência Nacional de Mineração editou a Resolução $\mathrm{n}^{\mathrm{O}} 4^{3}$, estabelecendo medidas para assegurar a estabilidade de barragens de mineração, proibindo a construção e alteamento de barragens pelo método a montante e vedando a utilização de FS abaixo de 1,3 para as análises de estabilidade e estudos de susceptibilidade à liquefação, considerando parâmetros de resistência não drenada. Por seu turno, a Secretaria Especial de Previdência e Trabalho do Ministério da Economia publicou, em 11 de abril de 2019 , a Portaria $\mathrm{n}^{\circ} 210^{28}$, vedando a concepção, construção, manutenção e funcionamento de instalações destinadas a atividades administrativas, de vivência, de saúde e de recreação nas áreas a jusante de barragens sujeitas à inundação em caso de rompimento, considerando tais situações de risco grave e iminente e passíveis de interdição.

\section{Contribuição de autoria}

Botelho MR, Faria MP, Mayr CTR e Oliveira LMG tiveram contribuição substancial na concepção do estudo, no levantamento, análise e interpretação dos dados, na elaboração e revisões críticas do manuscrito e na aprovação da versão final publicada. Todos os autores assumem responsabilidade pública integral pelo trabalho realizado e pelo conteúdo aqui publicado. 


\section{Referências}

1. Lima FPA, Diniz EH, Rocha R, Campos M. Barragens barreiras de prevenção e limites da segurança: para aprender com a catástrofe de Mariana. Rev Bras Saude Ocup [Internet]. 2015 [citado em 8 jun 2020];40(132):118-20. Disponível em: https://doi.org/10.1590/0303-7657ED02132115

2. Almeida IM, Jackson Filho JM, Vilela RAG. Razões para investigar a dimensão organizacional nas origens da catástrofe industrial da Vale em Brumadinho, Minas Gerais, Brasil. Cad Saude Publica [Internet]. 2019 [citado em 7 jun 2020];35(4):e000027319. Disponível em: https:// doi.org/10.1590/0102-311X00027319

3. Brasil. Ministério de Minas e Energia. Agência Nacional de Mineração. Resolução no ${ }^{\circ}$, de 15 de fevereiro de 2019. Diário Oficial da União [Internet]. 18 fev 2019 [citado em 15 nov 2021]:1:58. Disponível em: http://www.in.gov.br/ materia/-/asset_publisher/Kujrw0TZC2Mb/content/ id/63799094/do1-2019-02-18-resolucao-n-4-de-15de-fevereiro-de-2019-63799056

4. Agência Nacional de Mineração (BR). Relatório sintético da campanha de entrega de DCE: de março de 2020 [Internet]. Brasília, DF: Ministério de Minas e Energia (BR); 2020 [citado em 7 jun 2020]. Disponível em: https://mpmgbarragens.info/ wp-content/uploads/2020/04/Resumo-CampanhaEntrega-DCE-marco-2020-final.pdf

5. Brasil. Ministério do Trabalho e Previdência Social. Superintendência Regional do Trabalho e Emprego em Minas Gerais. Relatório de análise de acidente: rompimento da barragem de rejeitos Fundão em Mariana-MG [Internet]. Belo Horizonte: Superintendência Regional do Trabalho e Emprego em Minas Gerais; 2016 [citado em 6 jun 2020]. Disponível em: https://bit.ly/3CrNkbq

6. Brasil. Ministério da Economia. Superintendência Regional do Trabalho em Minas Gerais. Relatório de análise de acidente: rompimento da barragem B I da Vale S.A. em Brumadinho/MG em 25/01/2019 [Internet]. Belo Horizonte: Superintendência Regional do Trabalho e Emprego em Minas Gerais; 2019 [citado em 13 nov 2021]. Disponível em: https://sinait.org.br/docs/305346580-relatorio_bi__a_corpo_assinado.pdf

7. Llory M. Acidentes Industriais: o custo do silêncio. Operadores privados da palavra e executivos que não podem ser encontrados. Rio de Janeiro: Multimais; 1999.

8. Llory M, Montmayeul R. O acidente e a organização. Belo Horizonte: Fabrefactum; 2014.

9. Brasil. Ministério Público Federal. [Denúncia do Ministério Público Federal, Procuradoria do Estado de Minas Gerais e do Espírito Santo, protocolizada na Subseção Judiciária de Ponte Nova-Seção Judiciária do Estado de Minas Gerais contra a Samarco] [Internet]. Brasília, DF: Ministério Público Federa; 2016 [citado em 6 jun 2020].
Disponível em: http://www.mpf.mp.br/mg/sala-deimprensa/docs/denuncia-samarco

10. Brasil. Lei $\mathrm{n}^{\circ} 12.334$, de 20 de setembro de 2010. Diário Oficial da União [Internet]. 21 set 2010 [citado em 6 jun 2020];1:1 Disponível em: http://www.planalto.gov.br/ccivil_03/_ato20072010/2010/lei/l12334.htm

11. Brasil. Ministério de Minas e Energia. Departamento Nacional de Produção Mineral. Portaria n ${ }^{0}$ 70.389, de17 de maio de 2017. Diário Oficial da União [Internet]. 19 maio 2017 [citado em 13 nov 2021];1:68. Disponível em: https://www.in.gov.br/materia/-/asset_publisher/ Kujrw0TZC2Mb/content/id/20222904/do12017-05-19-portaria-n-70-389-de-17-de-maiode-2017-20222835

12. Soares L. Barragens de Rejeitos In: Luz AB, Sampaio JA, França SCA, editores. Tratamento de minérios. 5a ed. Rio de Janeiro: Centro de Tecnologia Mineral; 2010. p. 831-96.

13. Bittencourt C. Os dilemas do Novo Código da Mineração. Rio de Janeiro: Ibase; 2013.

14. Wanderley LJ, Mansur MS, Milanez B, Pinto RG. Desastre da Samarco/Vale/BHP no Vale do Rio Doce: aspectos econômicos, políticos e socioambientais. Cienc Cult [internet]. 2016 [citado em 6 jun 2020];68(3):30-5. Disponível em: http:// cienciaecultura.bvs.br/scielo.php?script =sci_arttex t\&pid =S0009-67252016000300011

15. D’Agostino LF. Praia de barragens de rejeitos de mineração: características e análise da sedimentação [tese]. São Paulo: Universidade de São Paulo; 2008.

16. Castro LVP. Avaliação do comportamento do nível d'água em barragem de contenção de rejeito alteada a montante [dissertação]. São Paulo: Universidade de São Paulo; 2008.

17. Machado WGF. Monitoramento de barragens de contenção de rejeitos da mineração [Dissertação]. São Paulo: Universidade de São Paulo; 2007.

18. Morgenstern NR, Vick SG, Viotti CB, Watts BD. Relatório sobre as causas imediatas da ruptura da barragem de Fundão [Internet]. [Local desconhecido]: Comitê de Especialistas para Análise da Ruptura da Barragem de Rejeitos de Fundão; 2016 [citado em 15 nov 2021]. Disponível em: https://www.fundacaorenova.org/wp-content/ uploads/2017/10/relatorio-sobre-as-causasimediatas-da-ruptura-da-barragem-de-fundao.pdf

19. Faria M, Botelho M. O rompimento da barragem de Fundão em Mariana, Minas Gerais, Brasil: a incubação de um acidente organizacional. Revista Portuguesa de Saúde Ocupacional Online [Internet]. 2018 [citado em 6 jun 2020];5:73-85. Disponível em: https:/www.rpso.pt/rompimentoda-barragem-fundao-mariana-minas-gerais-brasilincubacao-um-acidente-organizacional/. 
20. Faria MP, Botelho MR. A análise da causalidade do "acidente" de trabalho da Samarco. In: Pinheiro TMM, Polignano MV, Goulart EMA, Procópio JC, organizadores. Mar de lama da Samarco na bacia do rio Doce: em busca de respostas. Belo Horizonte: Instituto Guaicuy; 2019. p. 50-63.

21. Faria MP, Assunção AA. O abatimento mecanizado de rochas instáveis e segurança no trabalho em mina subterrânea de ouro. REFACS [Internet]. 2018 [citado em 6 jun 2020];6(Supl 2):54251. Disponível em: http://seer.uftm.edu.br/ revistaeletronica/index.php/refacs/article/ view/3124

22. Armstrong M, Petter R, Petter C. Why have so many tailings dams failed in recent years? Resour Policy [Internet]. 2019 [citado em 6 jun 2020];63:101412. Disponível em: https://doi. org/10.1016/j.resourpol.2019.101412

23. Milanez B, Magno L, Santos RSP, Coelho PT, Pinto RG, Gonçalves RJAF, et al. Minas não há mais: avaliação dos aspectos econômicos e institucionais do desastre da Vale na bacia do rio Paraopeba. Versos [Internet]. 2019 [citado em 6 jun 2020];3(1):1-114. Disponível em: https://www. ufjf.br/poemas/files/2017/04/Milanez-2019-Minasn\%c3\%a3o-h\%c3\%a1-mais-versos.pdf
24. Collins H, Pinch T. O Golen à solta: o que você deveria saber sobre tecnologia. Belo Horizonte: Fabrefactum; 2010.

25. Vaughan D. The trickle-down effect: policy decisions, risk work, and the Challenger Tragedy. Calif Manage Rev. 1997;39(2):80-102.

26. Mendel G. Prefácio. In: Llory M. Acidentes industriais: o custo do silêncio. Operadores privados da palavra e executivos que não podem ser encontrados. Rio de Janeiro: MultiMais; 1999. p. 11-23.

27. Minas Gerais. Lei $\mathrm{n}^{\mathrm{o}} 23.291$, de 25 de fevereiro de 2019. Diário Oficial do Estado de Minas Gerais [Internet]. 26 fev 2019 [citado em 6 jun 2020];1:1. Disponível em: https://www.jusbrasil. com.br/diarios/230292987/doemg-executivo-2602-2019-pg-1

28. Brasil. Ministério da Economia. Secretaria Especial de Previdência e Trabalho. Portaria $\mathrm{n}^{\circ} 210$, de 11 de abril de 2019. Diário Oficial da União [Internet]. 12 abr 2019 [citado em 6 jun 2020];1:55. Disponível em: http://www.in.gov. br/materia/-/asset_publisher/Kujrw0TZC2Mb/ content/id/71296599/do1-2019-04-12-portaria-n210-de-11-de-abril-de-2019-71296472 
No manuscrito: "Rompimento das barragens de Fundão e da Mina do Córrego do Feijão em Minas Gerais, Brasil: decisões organizacionais não tomadas e liçóes não aprendidas”, com número de DOI: 10.1590/2317-6369000018519, publicado no periódico Revista Brasileira de Saúde Ocupacional, 2021; 46:e16, corrige-se:

Na Introdução (página 2/10)

Onde se lê:

"pois 258 trabalhadores perderam a vida, sendo 12 da Vale, 118 terceirizados, 3 estagiários e mais 10 que trabalhavam fora da mina."

\section{Leia-se:}

"pois 258 trabalhadores perderam a vida, sendo 127 da Vale, 118 terceirizados, 3 estagiários e mais 10 que trabalhavam fora da mina."

Na Discussão (página 6/10)

Onde se lê:

"proporcionou à Vale receber autorização para sua descaracterizão"

\section{Leia-se:}

"proporcionou à Vale receber autorização para sua descaracterização" 